\title{
CONGENITAL ABNORMALITIES AS A POSSIBLE FACTOR IN THE AETIOLOGY OF POST-INTUBATION SUBGLOTTIC STENOSIS
}

\author{
D. J. STEWARD, M.B., B.S., DIP.ANAES., F.R.C.P.(C) ${ }^{\circ}$
}

Subglottic stenosis is one of the most serious complications of prolonged endotracheal intubation in children. The incidence of this complication has varied greatly in different reported series, and numerous aetiological factors have been suggested. ${ }^{1-4}$

Factors which may be involved in the production of subglottic stenosis include the following:

1. trauma at intubation,

2. duration of intubation,

3. external diameter of the tube,

4. composition of the tube,

5. methods used to sterilize the tube,

6. presence of upper airway infections,

7. movement of the tube relative to the patient (e.g. piston effect of the ventilator,

8. movement of the patient relative to the tube (e.g. struggling, convulsions),

9. attempts at phonation by the patient, coughing, or bucking,

10. inadequate humidification of gases,

11. systemic factors in the patient, among them, general debility, hypotension, anaemia, toxic states, deficiency diseases, dehydration, oedema, concurrent drug therapy, individual variation.

Prolonged nasotracheal intubation has been practised in the intensive care unit of the Hospital for Sick Children for several years, and, not surprisingly, longterm complications have occurred. ${ }^{3}$ However, subglottic stenosis is also seen in children with no previous history of endotracheal intubation, and to approach this problem from a different aspect it was considered worthwhile to review a series of cases of this condition. These cases included children with and without a history of endotracheal intubation.

\section{METHOD OF STUdy}

From the operating room records it was possible to list every child examined endoscopically in whom a diagnosis of subglottic stenosis was suspected. A period of six months was reviewed, and 30 cases were studied. Twenty-two of these cases were found to have been definitely diagnosed as varying degrees of subglottic stenosis. Most of the patients had no previous history of intubation. Congenital

\footnotetext{
'Department of Anaesthesia, Hospital for Sick Children, Toronto, and the University of Toronto.

Canad. Anaesth. Soc. J., vol. 17, no. 4, July 1970 
stenosis accounted for 16 of the 22 cases, and post-infection and post-intubation stenosis for three cases each.

Aetiology was decided by reviewing the medical records of each patient and correlating these with the opinion of the laryngologist who performed the endoscopy. The largest group of patients - those with congenital subglottic stenosis had no history of previous intubation. The post-infection group all had a history of tracheitis; none of these had been treated with an endotracheal tube. The postintubation group had all been intubated for more than 48 hours for various reasons.

In order to study further the group with congenital subglottic stenosis, their records were examined to determine how many had other congenital anomalies. We found three cases of innominate artery compression of the trachea, two cases of Downs' syndrome, and one each of ventricular septal defect, AV communis, hypoplastic right lung, cleft palate, Pierre-Robin syndrome, trachesophageal fistula, and laryngeal web. Thus in sixteen patients with congenital subglottic stenosis, twelve had other defects present as well.

\section{Discussion}

Many factors have been previously implicated in the production of subglottic stenosis. The fact that some patients may have a pre-existing degree of congenital stenosis has been largely overlooked. The finding that congenital subglottic stenosis is often associated with other congenital lesions, which may require surgery, is of considerable significance to the paediatric anaesthetist. Intubation would be required during surgery in many of these cases, and some might require postoperative ventilatory support through an endotracheal tube. Unless the possibility of congenital subglottic stenosis is considered, further damage may be caused by a tight-fitting tube. The subsequent appearance of stenosis would then likely be attributed entirely to the intubation.

Thus, in treating children with any form of congenital defect, narrowing of the airway should be suspected and suitable caution exercised in the selection of the correct size of endotracheal tube.

\section{Summary}

An examination of case histories of children with subglottic stenosis reveals that this condition is frequently congenital in origin and is often associated with other congenital defects. The importance of this fact to the paediatric anaesthetist, and to those concerned with paediatric intensive care, is stressed.

\section{RÉSUMÉ}

Jusqu'à maintenant, on a attribué à plusieurs facteurs la sténose sous-glottique. Le fait que certains cas peuvent présenter plus ou moins de sténose congénitale pré-existante a été largement considéré. La constatation que la sténose sous-glottique congénitale est souvent associé à d'autres lésions congénitales, qui peuvent 
demander un traitement chirurgical, est très intéressante pour l'anesthésiste en pédiatrie. Pour plusieurs de ces cas, l'intubation pourrait être nécessaire durant lintervention, et quelques uns pourraient avoir besoin de ventilation postopératoire à l'aide d'un tube endotrachéal. Si l'on ne tient pas compte de la possibilité d'une sténose sous-glottique congénitale, on peut causer un dommage additionnel en utilisant un tube trop juste. L'apparition subséquente de sténose serait vraisemblablement attribuée à la seule intubation.

Ainsi, lorsqu'on traite des enfants porteurs de quelque forme que ce soit d'anomalies congénitales, on devrait toujours soupçonner un rétrécissement des voies aériennes supérieures, et être très prudent dans le choix du tube endotrachéal.

\section{ACKNOWLEDGMENTS}

The author wishes to thank the members of the department of otorhinolaryngology of the Hospital for Sick Children, Toronto, for permission to publish details of the cases reviewed, and for assistance in making this survey.

\section{REFERENCES}

1. HolmoafL, M. H. \& Lindholm, C. Prolonged Oro-naso-tracheal Intubation in Children. Acta Otolaryngol. Suppl. 224: 409 (1966).

2. Struker, T. W.; SToor, S.; \& Downes, J. J. Prolonged Nasotracheal Intubation in Infants and Children. Arch Otolaryngol. 85: 210 (1967).

3. Fearon, B.; MacDonald, R. E.; Smith, C.; \& Mrtchell, D. Airway Problems in Children Following Prolonged Endotracheal Intubation. Ann. Otol. Rhin. \& Laryngol. 75: 975 (1966).

4. Allen, T. H. \& Steven, I. M. Prolonged Endotracheal Intubation in Infants and Children. Brit. J. Anaesth. 37: 566 (1965). 